\title{
Gesture and Joystick Controlled Multipurpose Automated Wheelchair
}

\author{
Mallikharjuna Rao Sathuluri, Santhikiran Bathulla, Abdul Azeem and Y. Pavan Kumar \\ Department of Electronics and Communication Engineering, Andhra Loyola Institute of Engineering and \\ Technology, Vijayawada - 520008, Andhra Pradesh, India; smr.aliet@gmail.com, bsk.aliet@gmail.com, \\ aazeem83@gmail.com, pavan670@gmail.com
}

\begin{abstract}
Objective: The main objective of this paper is to explore the importance of advanced wheelchair which can substitute a better service for the physically challenged. According to livable hood, it is estimated that 10, 000, 0000 people are in the dire need of a wheel chair and it is also estimated that 156 developing countries are in need of it. Methods/Statistical Analysis: The automated wheelchair has a creative design with an ultrasonic sensor and a joystick controlled facility. It further includes a gesture controlled system for the comfort of individuals. This analytic method tries to focus on the importance of the advanced wheelchair in the $21^{\text {st }}$ century. Finding: The ultrasonic sensor detects the objects and measures the distance. The MEMS based accelerometer ADXL335 sensor gives reading based on the change in the acceleration due to gravity analyzing. For achieving all the above actions, we are using Arduino MEGA2560 development board since it is easy to use with above mentioned modules and also the program. Applications/improvements: This paper tries to explore the highlights of creative joystick and gesture controlled wheelchair which can make the life of individual comfortable and happy.
\end{abstract}

Keywords: Accelerometer ADXL335, Arduino MEGA (2560), Gesture System, Ultrasonic Sensor, Wheel Chair

\section{Introduction}

The capabilities of traditionally powered devices are introduced strongly by the automated wheelchair. These devices are useful mainly for the physically challenged in performing their daily tasks in a comfortable manner without taking the help of other person. So, the joystick and gesture controlled wheelchair provides automation which is very important for livable hood ${ }^{1}$.

This project aims to highlight some concerns desirable for their happy moving in the environment. The automated wheelchair can serve great purpose with the use of a microcontroller and motor driving. The above mentioned method can be more compatible than that of ordinary wheelchair.

The basic block diagram of the proposed system is indicated in Figure 1. The proposed system employsAT mega2560 microcontroller as a control unit. It has 54 pins in total out of which 16 are used for analog input pins and remaining pins are used for interface. The automated wheelchair can be operated in three modes: First mode is Automated mode in which ultrasonic sensor is deployed to identify and avoid the obstacles ${ }^{1,2}$. Second mode is joystick mode where the system is controlled manually. Third mode is gesture controlled mode in which accelerometer sensor is controlled based on MEMS technology ${ }^{3}$.

The automated wheelchair has following advantages: Firstly for avoiding the obstacles, secondly the distance measurements using ultrasonic sensor and thirdly for gesture based control of wheelchair.

To sum up, the above mentioned advantages can be used as the modules for the Arduino IDE in developing the programming system. Here the output values are based on the change in the acceleration due to gravity and

${ }^{*}$ Author for correspondence 
by proper analysis we can obtain the same values in terms of angle measurement. Even though the sensor is having three axis output pins we use only two axis pin outputs i.e., $x$-pin and y-pin ${ }^{1}$.

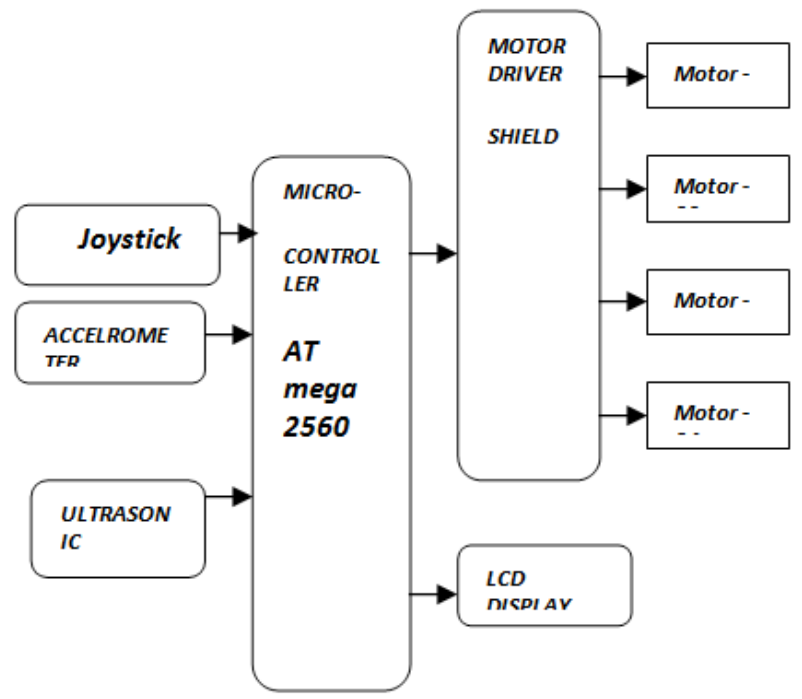

Figure 1. Block Diagram of Proposed System.

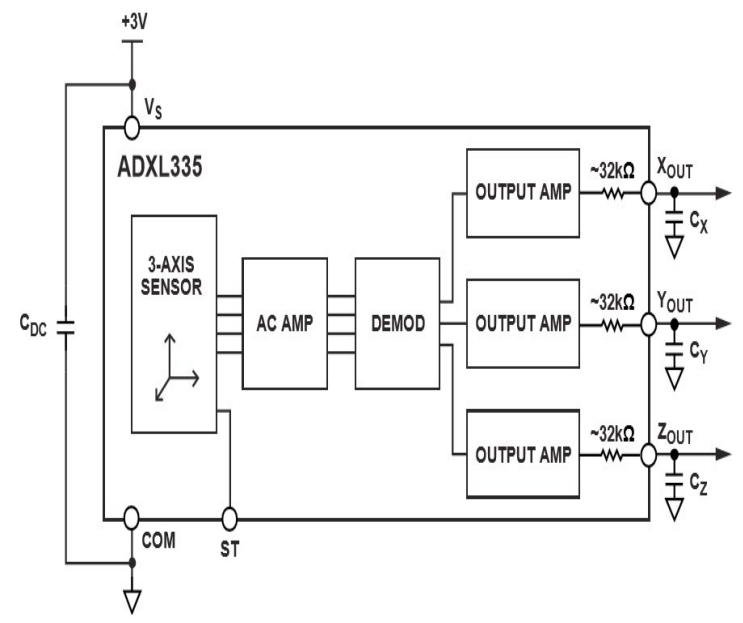

Figure 2. ADXL 335 Block Diagram.

\section{Prototype Design}

At the stage of prototyping the design, the following components are used:

\subsection{Arduino Board}

For the ease of programming, ATmega2560 microcontroller is preferred. So, we use Arduino MEGA development board using in built ATmega2560 controller. It has 54 pins out of which 16 pins are Analog input pins and 15 are PWM output pins along with $8 \mathrm{~KB}$ SRAM, $4 \mathrm{~KB}$ EEPROM and 256KB Flash memory.

\subsection{Accelerometer/ADXL 335}

The ADXL335 has a 3-axis acceleration estimation framework. The ADXL335 needs an estimation extent about \pm 3 $\mathrm{g}$ least. The yield signs need to aid simple voltages proportional to the acceleration. The accelerometer measures the static acceleration of gravity in tilt-sensing provisions and element acceleration due to motion, shock, alternately vibration $^{1,4}$.

\subsubsection{Calculation of Bandwidth using $C_{X}, C_{P}$ and $\mathrm{C}_{\mathrm{Z}}$}

The ADXL335 which has provisions for band limiting the $\mathrm{X}_{\text {OUT }}, \mathrm{Y}_{\text {OUT }}$ and $\mathrm{Z}_{\text {OUT }}$ pins.

The equation for the $3 \mathrm{~dB}$ bandwidth is:

$\mathrm{F}-3 \mathrm{~dB}=1 /\left(2 \pi(32 \mathrm{k} \Omega){ }^{\star} \mathrm{C}(\mathrm{X}, \mathrm{Y}, \mathrm{Z})\right)$

Or

$\mathrm{F}-3 \mathrm{~dB}=5 \mu \mathrm{F} / \mathrm{C}(\mathrm{X}, \mathrm{Y}, \mathrm{Z})$

Table 1 and 2 show typically the commonplace RMS clamor of the ADXL335 which will be dictated by:

rms Noise $=$ Noise Density ${ }^{\star}\left(\sqrt{ }\left(B . W^{\star} 1.6\right)\right)$

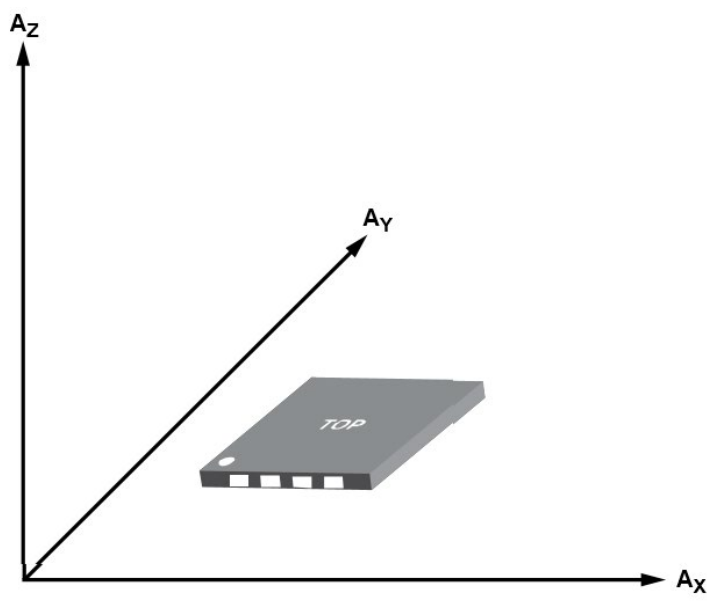

Figure 3. Axes of Acceleration.

Table 1. Filter Capacitor Selection

\begin{tabular}{|l|l|}
\hline Bandwidth $(\mathrm{Hz})$ & Capacitor $(\mu \mathrm{F})$ \\
\hline 1 & 4.7 \\
\hline 10 & 0.47 \\
\hline 50 & 0.10 \\
\hline
\end{tabular}




\begin{tabular}{|l|l|}
\hline 100 & 0.05 \\
\hline 200 & 0.027 \\
\hline 500 & 0.01 \\
\hline
\end{tabular}

Table 2. Calculationof Peak to Peak Noise

\begin{tabular}{|l|l|}
\hline P-P Value & $\begin{array}{l}\text { \% of Time that Noise exceeds } \\
\text { Nominal Peak to Peak Value }\end{array}$ \\
\hline $2^{\star} \mathrm{rms}$ & 32 \\
\hline $4^{\star} \mathrm{rms}$ & 4.6 \\
\hline $6^{\star} \mathrm{rms}$ & 0.27 \\
\hline $8^{\star} \mathrm{rms}$ & 0.006 \\
\hline
\end{tabular}

The Axes of Acceleration is represented in Figure 3. The Sensitivity and corresponding Output Voltage increases when accelerated along the Sensitive Axis.

In the Proposed System, totally 5 types of Gestures are being used which are mentioned in Table 3.

Table 3. Output values for various gestures

\begin{tabular}{|l|l|}
\hline Movement State & Sensor output values \\
\hline No movement & $513<\mathrm{x}<521 ; 512<\mathrm{y}<518$ \\
\hline Forward & $506<\mathrm{x}<514 ; 529<\mathrm{y}<537$ \\
\hline Backward & $512<\mathrm{x}<515 ; 411<\mathrm{y}<418$ \\
\hline Left & $511<\mathrm{x}<529 ; 528<\mathrm{y}<537$ \\
\hline Right & $586<\mathrm{x}<589 ; 522<\mathrm{y}<529$ \\
\hline
\end{tabular}

\subsection{Ultrasonic Sensor (HC-SR04)}

The HC - SR04 is an Ultrasonic ranging module provides $2 \mathrm{~cm}-400 \mathrm{~cm}$ non-contact measurement function. It has accuracy up to $3 \mathrm{~mm}$. The modules includes ultrasonic transmitters, receiver and control unit ${ }^{2,4}$.

\subsubsection{Distance Measurement Principle}

The transmitter emits 8 bursts of a directional $40 \mathrm{kHz}$ ultra nationalistic wave. Ultra nationalistic pulses head out outward until they experience an object; those objects make the wave to reflect back towards the transmitter. The speed of the ultra nationalistic blast is $340 \mathrm{~m} / \mathrm{sec}$ in air.

The time (or) rate (or) distance measurement formula is:

$$
\begin{aligned}
& \mathbf{D}=\mathbf{C}^{\star} \mathbf{T} \\
& \text { Where } \quad \mathrm{D}=\text { Measured distance } \\
& \mathrm{C}=\text { Propagation velocity } \\
& \mathrm{T}=\text { Time }
\end{aligned}
$$

For ease of understanding in accordance with our project the distance measurement can be expressed as

\section{Distance $=\left(\right.$ Echo high level time ${ }^{\star}$ Velocity of Ultrasonic}

\section{(Sound Velocity in air $340 \mathrm{~m} / \mathrm{sec})) / 2$}

The automated system consisting of servo attached along with the Ultrasonic sensor and setup is shown in Figure 10.

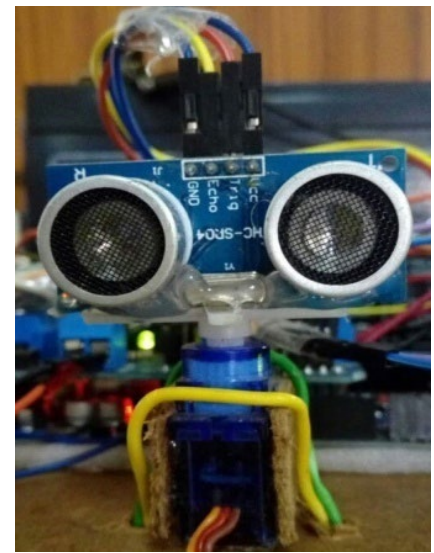

Figure 4. During initial stage scan for obstacle in straight line path.

Here the ultrasonic sensor is deployed to detect the object at distance of $15 \mathrm{cms}$, where below that value; the system will stop moving and starts scanning in the left and right directions for moving. The timing diagram of Ultrasonic module and input signal fed to the servo motor are indicated in Figures 5\&6.

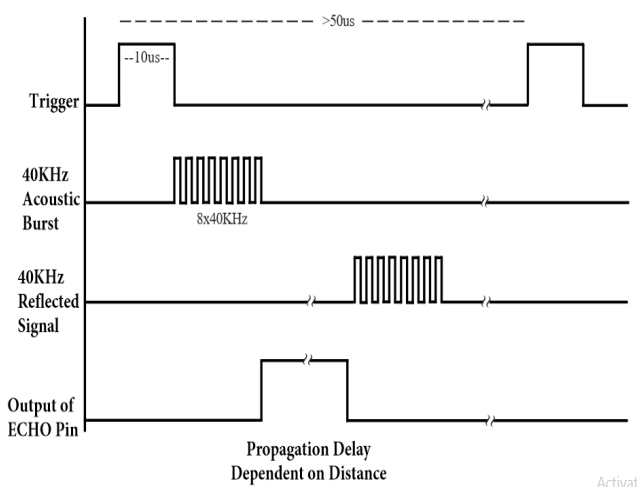

Figure 5. Timing Diagram of Ultrasonic Module.

The process of scanning in the rightward and leftward directions by the automated system consisting of servo attached along with the Ultrasonic sensor is shown in Figures 7 and 8. 


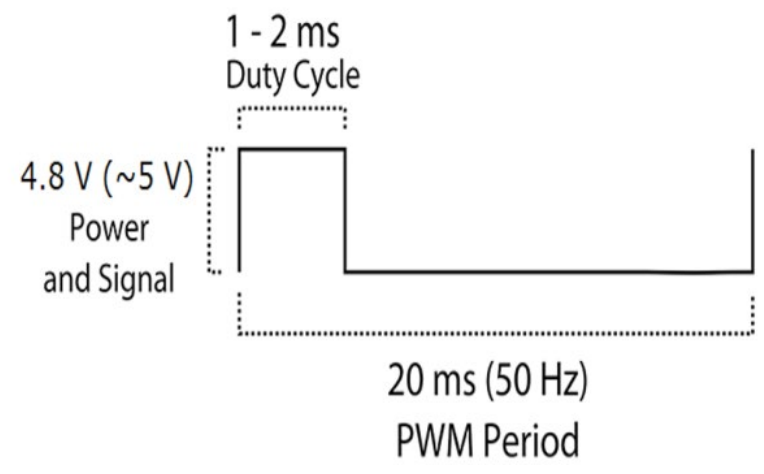

Figure 6. Timing Diagram of Input signal fed to servo.

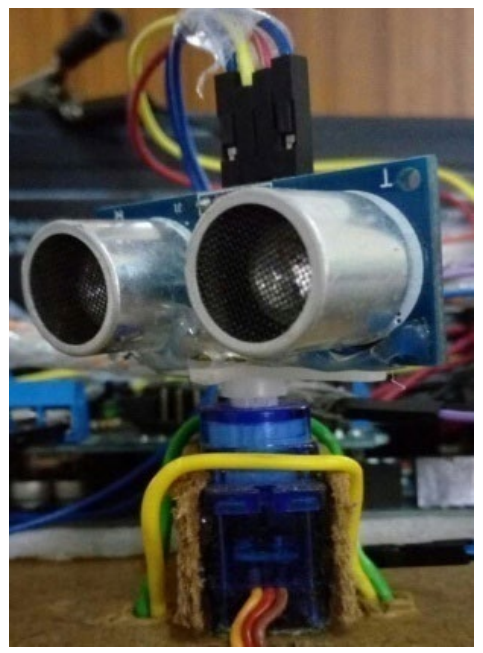

Figure 7. Scanning in the Rightward direction.

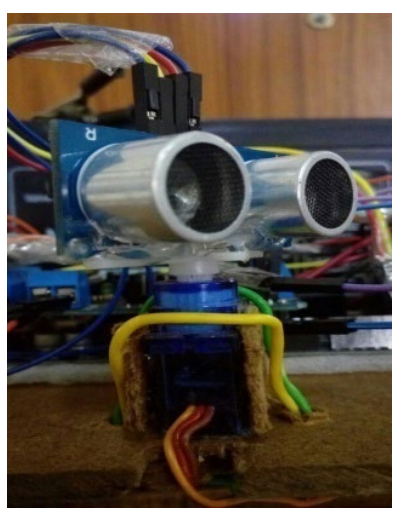

Figure 8. Scanning in the Leftward Direction.

\section{Results and Discussion}

The automated wheelchair has a creative design with an ultrasonic sensor and a joystick controlled facility. It includes a gesture controlled system for the comfort of individuals. The analysis result of proposed method is as follows.

\subsection{Software Results}

The Figure 9 shows the distance measurement values i.e, the distance between the object and the system. If the distance between them is less than the pre-determined value, then the system starts moving in the corresponding directions.

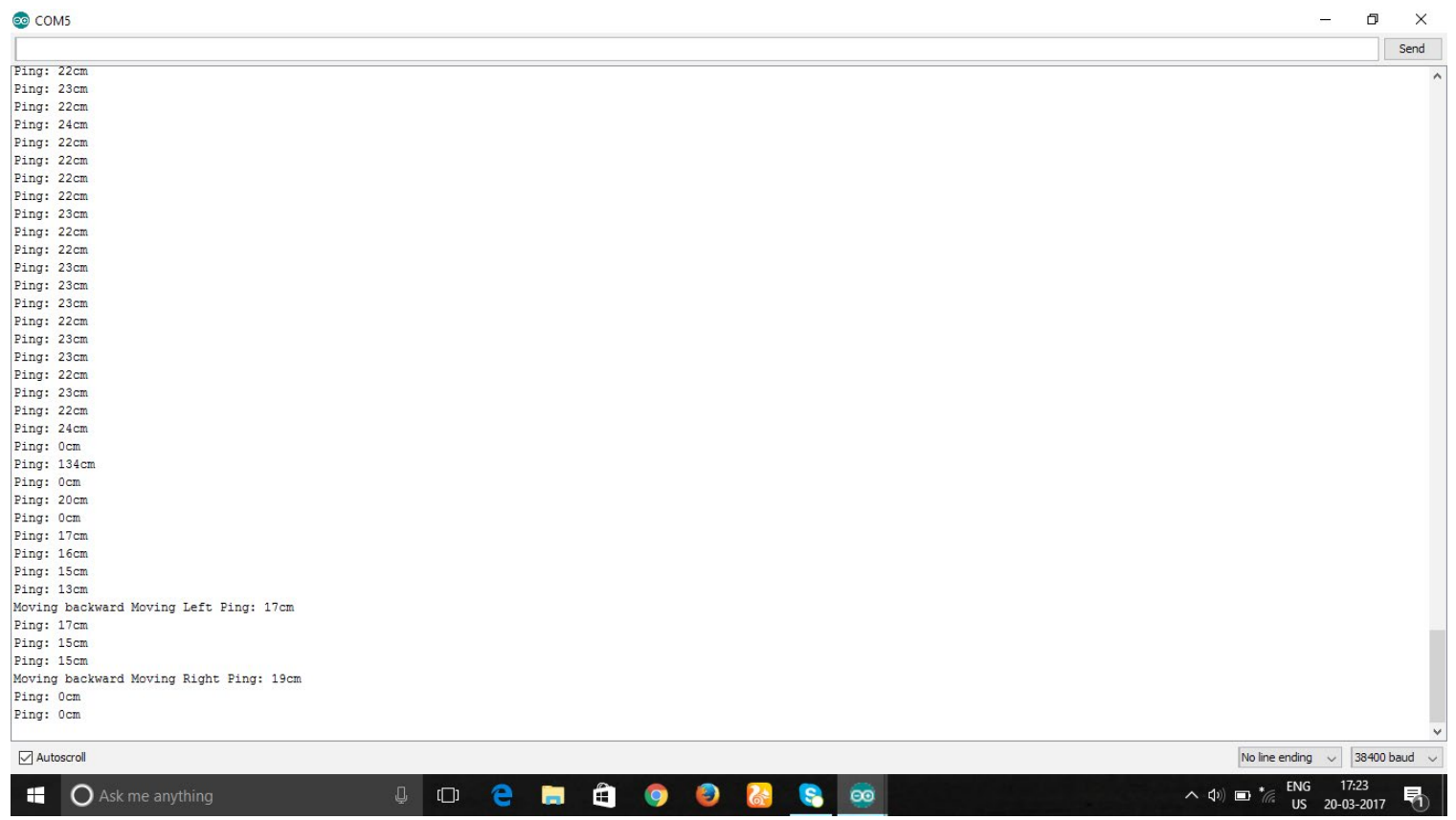

Figure 9. Distance Measurement Values. 


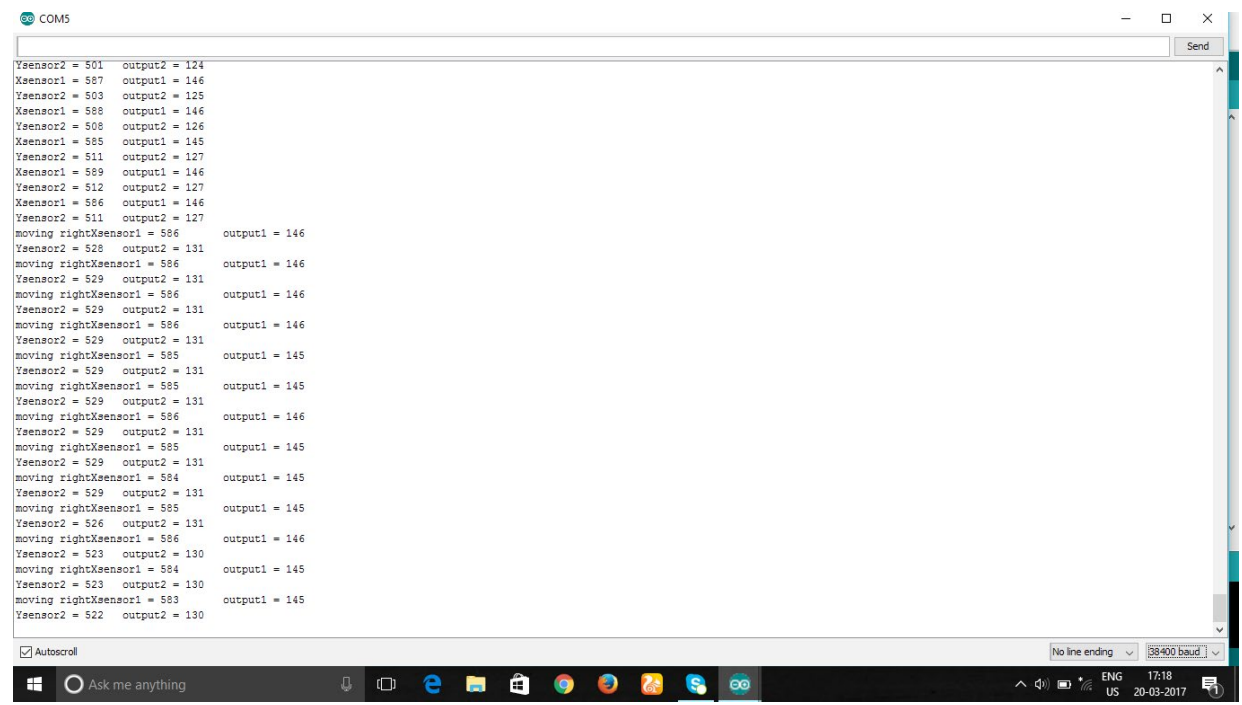

Figure 10. System moving right side for corresponding output values.

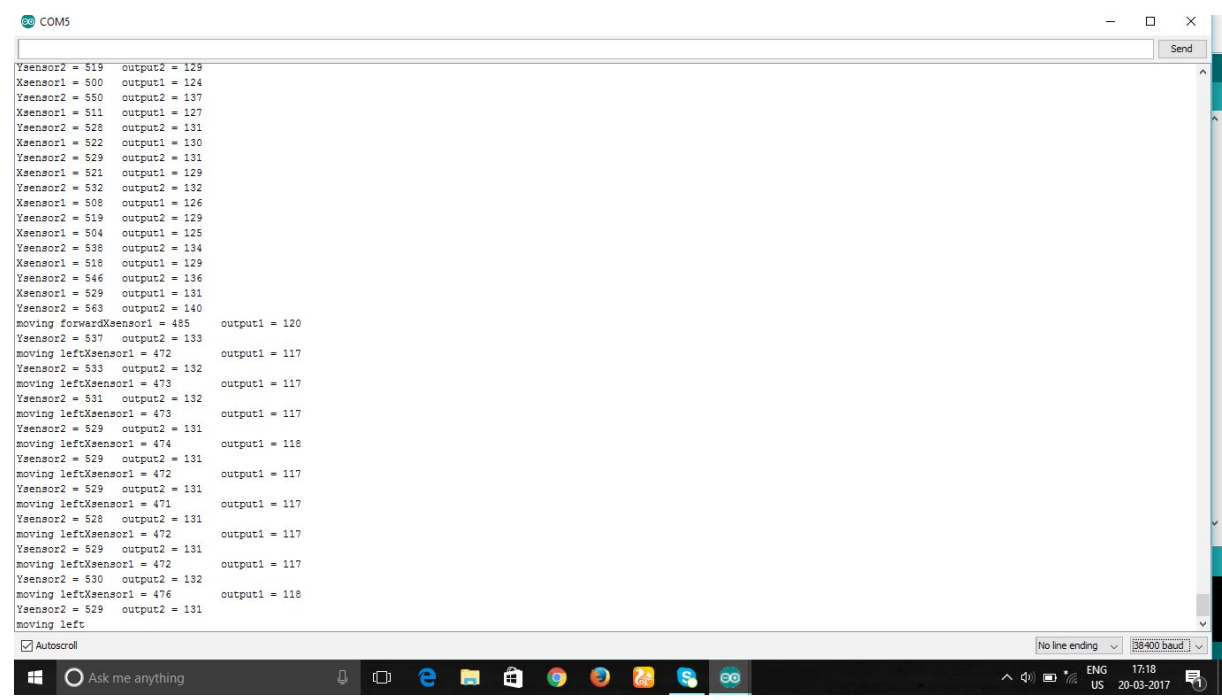

Figure 11. System moving left side for corresponding output values.

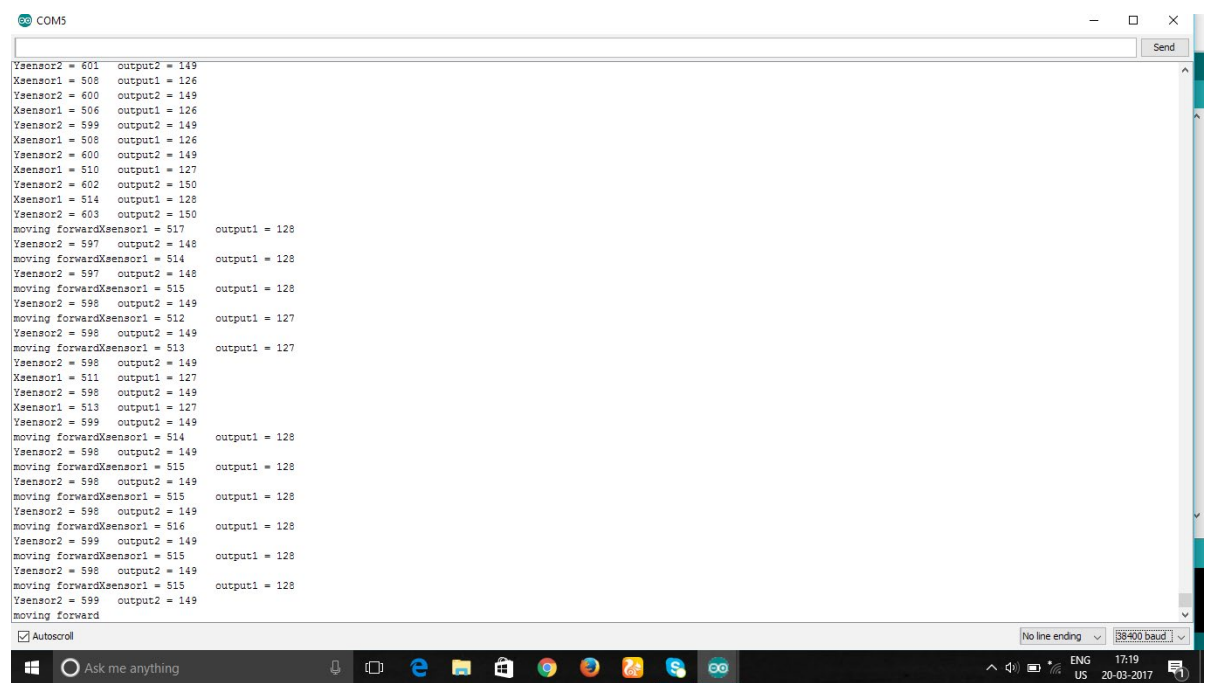

Figure 12. System moving forward for corresponding output values. 


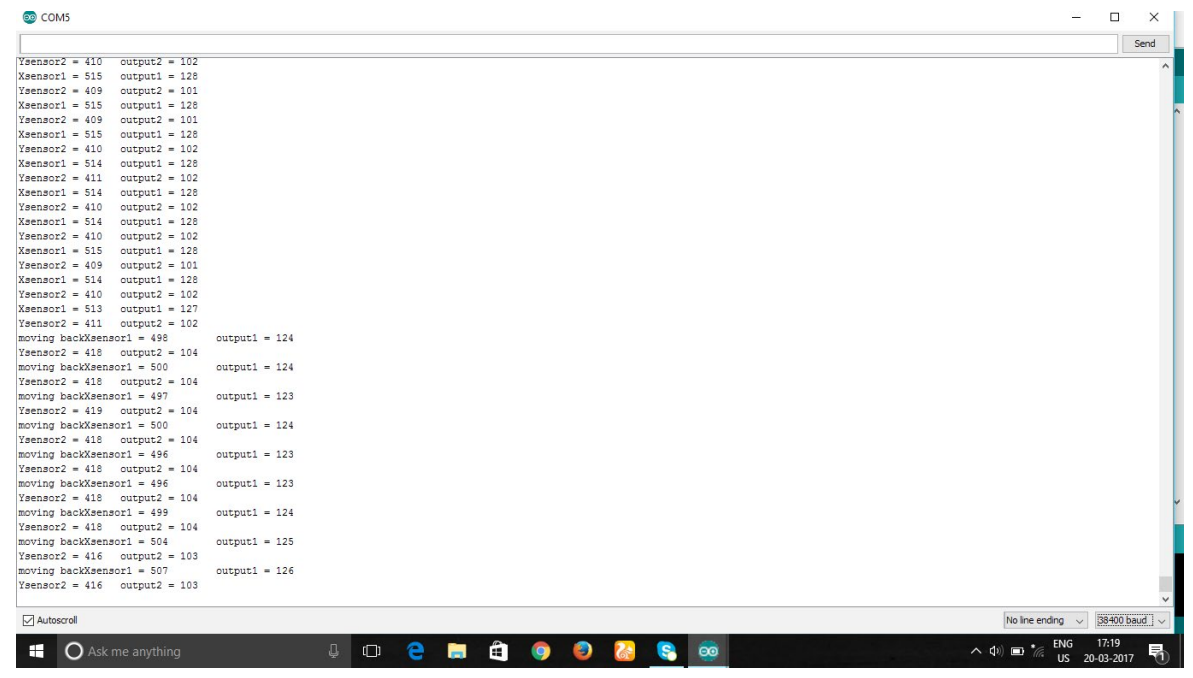

Figure 13. System moving backward for corresponding values.

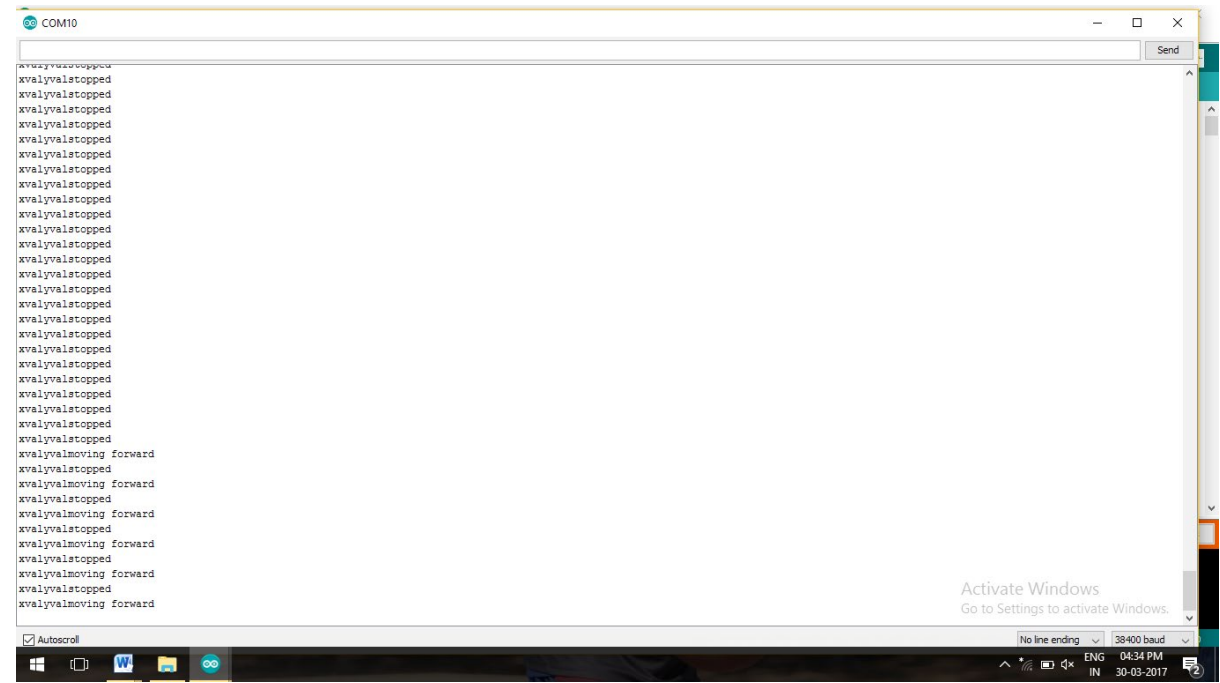

Figure 14. System movement in forward direction for corresponding action.

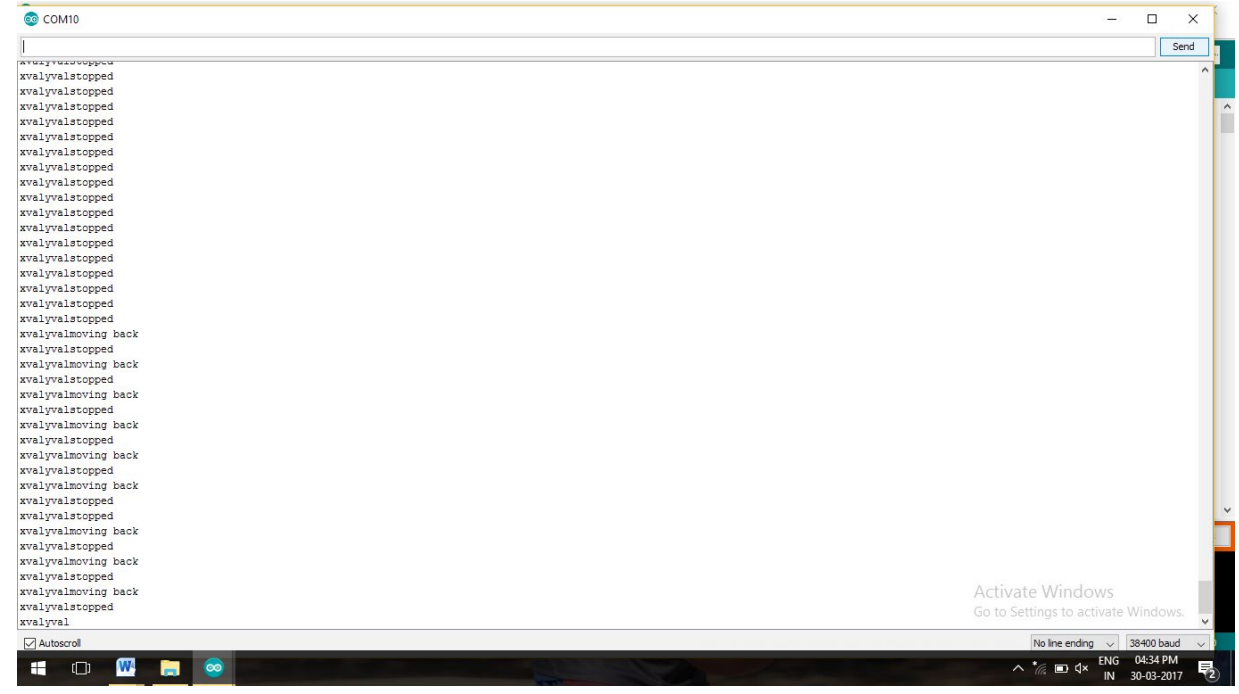

Figure 15. System movement in backward direction for corresponding action. 


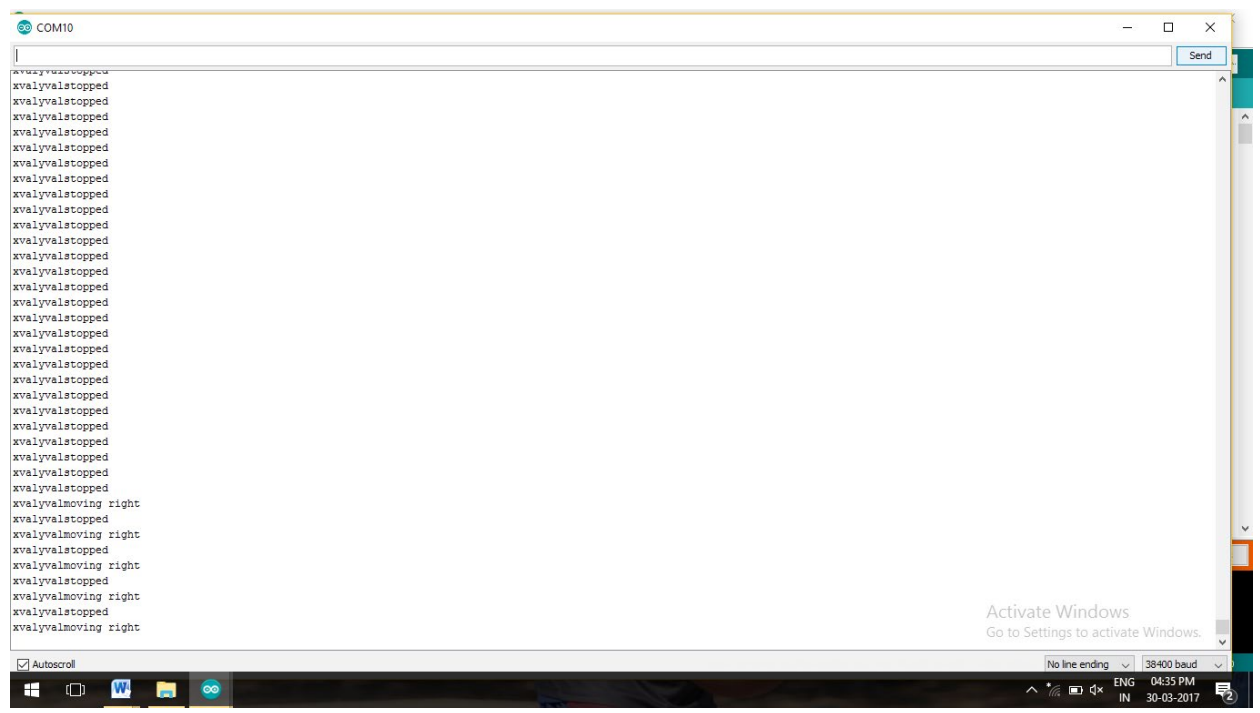

Figure 16. System movement in right direction for corresponding action.

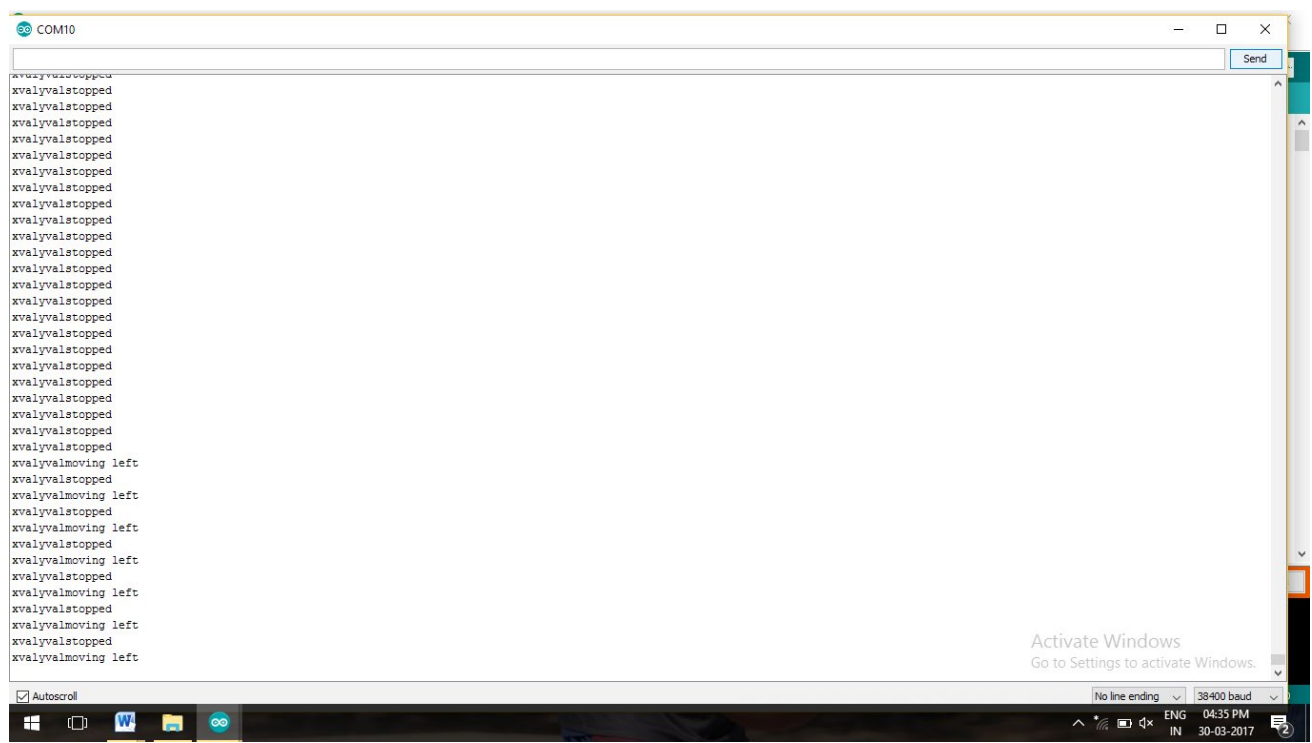

Figure 17. System movement in left direction for corresponding action.

Table 4. Hardware results of Automated system for Corresponding actions

\begin{tabular}{|c|c|c|c|c|c|c|}
\hline \multicolumn{2}{|l|}{ CONDITION } & DISTANCE & M1 & M2 & M3 & M4 \\
\hline \multicolumn{2}{|l|}{ INITIAL } & DISTANCE $<15 \mathrm{~cm}$ & $+4.8 \mathrm{~V}$ & $+3.98 \mathrm{~V}$ & $+4.2 \mathrm{~V}$ & $+4.3 \mathrm{~V}$ \\
\hline \multirow[t]{2}{*}{$\begin{array}{l}\text { OBSTACLE } \\
\text { ENCOUNTERED }\end{array}$} & $\begin{array}{l}\text { Left } \\
\text { movement }\end{array}$ & $\begin{array}{l}\text { DistanceL }> \\
\text { DistanceR(distace }>15 \mathrm{~cm})\end{array}$ & $-4.07 \mathrm{~V}$ & $+4.50 \mathrm{~V}$ & $-4.60 \mathrm{~V}$ & $+4.7 \mathrm{~V}$ \\
\hline & $\begin{array}{l}\text { Right } \\
\text { movement }\end{array}$ & $\begin{array}{l}\text { DistanceR }> \\
\text { DistanceL }(\text { distance }>15 \mathrm{~cm})\end{array}$ & $+4.35 \mathrm{~V}$ & $-3.98 \mathrm{~V}$ & $+4.40 \mathrm{~V}$ & $-4.75 \mathrm{~V}$ \\
\hline
\end{tabular}


Table 5. Hardware results of Gesture system for Corresponding actions

\begin{tabular}{|c|c|c|c|c|c|c|c|c|}
\hline \multirow[t]{2}{*}{ CONDITION } & \multicolumn{2}{|c|}{ EXPECTED VALUE } & \multicolumn{2}{|c|}{ RESULTANT VALUE } & \multirow[t]{2}{*}{ M1 } & \multirow[t]{2}{*}{ M2 } & \multirow[t]{2}{*}{ M3 } & \multirow[t]{2}{*}{ M4 } \\
\hline & X-AXIS & Y-AXIS & X-AXIS & Y-AXIS & & & & \\
\hline FORWARD & $>512$ & $>560$ & 524 & 573 & $+4.8 \mathrm{~V}$ & $+3.98 \mathrm{~V}$ & $+4.2 \mathrm{~V}$ & $+4.3 \mathrm{~V}$ \\
\hline BACK & $<514$ & $>463$ & 506 & 489 & $+4.07 \mathrm{~V}$ & $+4.50 \mathrm{~V}$ & $+4.60 \mathrm{~V}$ & $+4.7 \mathrm{~V}$ \\
\hline LEFT & $<486$ & $>508$ & 437 & 512 & $+4.35 \mathrm{~V}$ & $-3.98 \mathrm{~V}$ & $+4.40 \mathrm{~V}$ & $-4.75 \mathrm{~V}$ \\
\hline RIGHT & $>550$ & $>512$ & 564 & 586 & $-4.63 \mathrm{~V}$ & $+4.84 \mathrm{~V}$ & $-4.28 \mathrm{~V}$ & $+4.38 \mathrm{~V}$ \\
\hline STOP & $\begin{array}{l}\text { REMAINING } \\
\text { VALUES }\end{array}$ & $\begin{array}{l}\text { REMAINING } \\
\text { VALUES }\end{array}$ & $\begin{array}{l}\text { REMAINING } \\
\text { VALUES }\end{array}$ & $\begin{array}{l}\text { REMAINING } \\
\text { VALUES }\end{array}$ & $0.2 \mathrm{~V}$ & $0.12 \mathrm{~V}$ & $0.31 \mathrm{~V}$ & $0.31 \mathrm{~V}$ \\
\hline
\end{tabular}

Table 6. Hardware results of joystick system for Corresponding actions

\begin{tabular}{|l|l|l|l|l|l|l|l|l|}
\hline \multirow{2}{*}{ CONDITION } & \multicolumn{2}{l}{ EXPECTED VALUE } & \multicolumn{2}{l|}{ RESULTANT VALUE } & M1 & M2 & \multirow{2}{*}{ M3 } & M4 \\
\cline { 2 - 6 } & X-AXIS & Y-AXIS & X-AXIS & Y-AXIS & & & & \\
\hline FORWARD & $1021-1023$ & $515-517$ & 1023 & 516 & $+4.07 \mathrm{~V}$ & $+4.50 \mathrm{~V}$ & $+4.60 \mathrm{~V}$ & $+4.7 \mathrm{~V}$ \\
\hline BACK & $0-3$ & $515-518$ & 0 & 516 & $-4.8 \mathrm{~V}$ & $-3.98 \mathrm{~V}$ & $-4.2 \mathrm{~V}$ & $-4.3 \mathrm{~V}$ \\
\hline LEFT & $508-511$ & $0-3$ & 509 & 0 & $-4.63 \mathrm{~V}$ & $+4.84 \mathrm{~V}$ & $-4.28 \mathrm{~V}$ & $+4.38 \mathrm{~V}$ \\
\hline RIGHT & $509-511$ & $1021-1023$ & 510 & 1023 & $+4.35 \mathrm{~V}$ & $-3.98 \mathrm{~V}$ & $+4.40 \mathrm{~V}$ & $-4.75 \mathrm{~V}$ \\
\hline STOP & $510-512$ & $520-525$ & 512 & 524 & $0.31 \mathrm{~V}$ & $0.2 \mathrm{~V}$ & $0.12 \mathrm{~V}$ & $0.26 \mathrm{~V}$ \\
\hline
\end{tabular}

The Figure 10 shows the system is moving in right side and the corresponding values of Xout and Yout values displayed.

The Figure 11 shows the system is moving in lest side and the corresponding values of Xout and Yout values displayed.

The Figure 12 shows the system is moving in lest side and the corresponding values of Xout and Yout values displayed.

The Figure 13 shows the system is moving in lest side and the corresponding values of Xout and Yout values displayed.

The Figure 14 shows the system is moving forward and the corresponding values of $\mathrm{Vx}$ and $\mathrm{Vy}$ values displayed.

The Figure 15 shows the system is moving backward and the corresponding values of $\mathrm{Vx}$ and $\mathrm{Vy}$ values displayed.

The Figure 16 shows the system is moving right side and the corresponding values of $\mathrm{Vx}$ and $\mathrm{Vy}$ values displayed.
The Figure 17 shows the system is moving left side and the corresponding values of $\mathrm{Vx}$ and Vy values displayed.

\subsection{Hardware Results}

The Table 4 shows the measured hardware output values for Automated system in different conditions and situations. We have measured the voltage levels at every stage and even the distance.

The Table 5 shows the measured hardware output values for Gesture system in different conditions and situations. We have measured the voltage levels at every stage and the acceleration due to gravity values from the accelerometer. Using those values the certain actions are performed.

The Table 6 shows the measured the hardware output values for joystick mode in different conditions and situations. We have measured the voltage levels at every stage and the variations in the resistance of the joystick module are measured. Using those values the certain actions are performed.

The overall prototype design is shown in the Figure 18. 


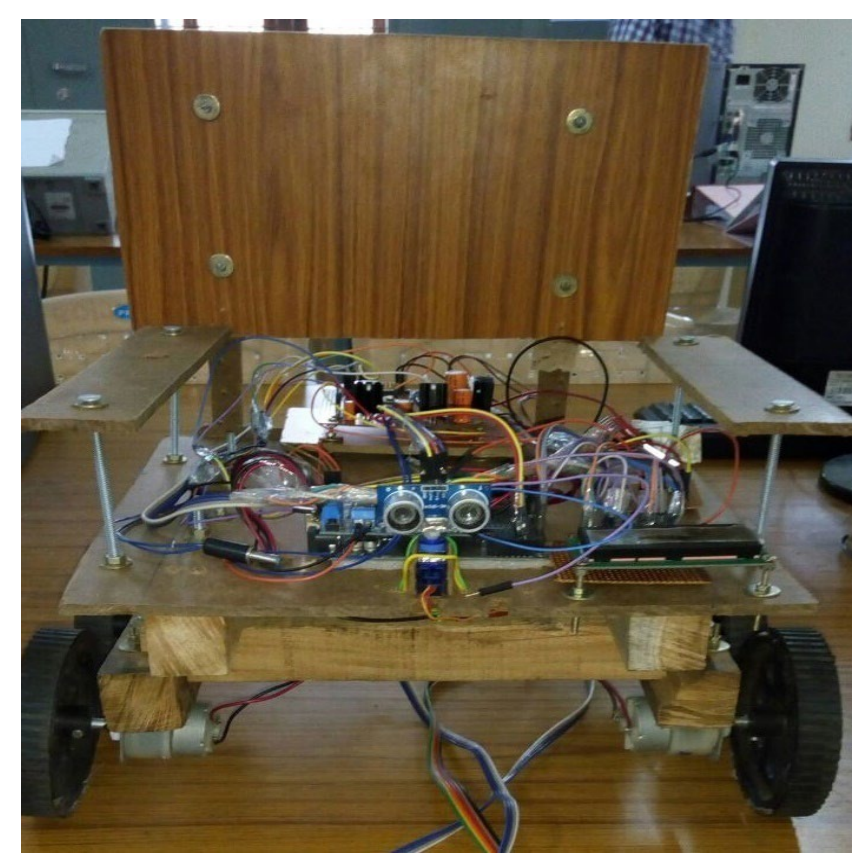

Figure 18. Final Setup with all the modes.

\section{Conclusion}

The Proposed System of automated wheelchair provides access for multiple users mainly, the persons with disabili- ties. With the use of this system, we will make the persons feel energetic and relax from physical and mental stress. In addition, using this system the physically challenged can perform their daily tasks without any risk. It is a great benefit for the people to be re-energized and to regain their strength to move forward courageously and to have bright hope in their future.

\section{References}

1. Manogna S, Vaishnavi S. Head Movement Based Assist System for Physically Challenged. 2010.

2. Kuno Y, Murashima T, Shimada N, Shirai Y. Interactive Gesture Interface for Intelligent Wheelchairs. IEEE Conference on multimedia and expo ICME. 2000. Crossref.

3. Sakib SN, Mouri SP, Ferdous Z, Shamim Kaiser M. A Study on Low Cost Solar Powered Wheel Chair for Disabled People of Bangladesh. 2015.

4. Ramamohan C, Vishnu Vardhan D. Obstacle detection and navigation system for impaired people. 2016 Aug; 5(8):1-6. 